\title{
Incidence, types and outcomes of sternal wound infections after cardiac surgery in Saudi Arabia
}

\author{
$A$ retrospective medical chart review
}

Fahad M. Al Majid, FRCP, ABIM, Faruk Buba, FWACP, MRCP, Mazen Barry, FRCPC, FACP, Fatima Alsharani, ABIM, Fawzan Alfawzan, MD.

\begin{abstract}

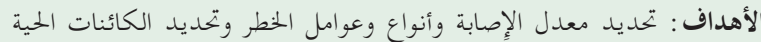

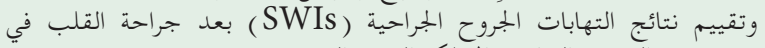
مستشفى ثالثي في الرياض، المملكة العربية السعودية .

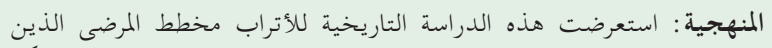

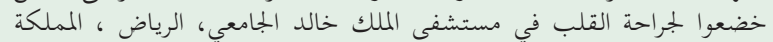

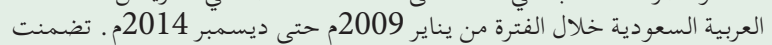

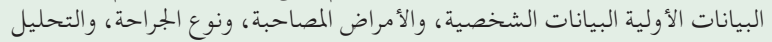
الميكروبيولوجي، ونتائج الإدارة.

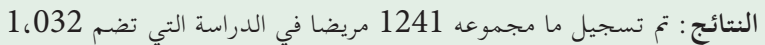

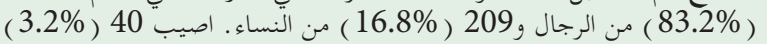

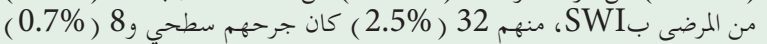

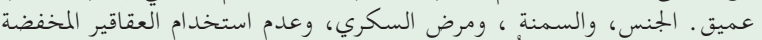

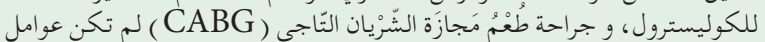

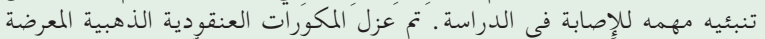

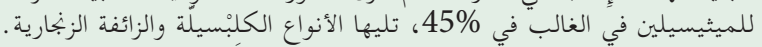

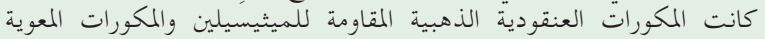

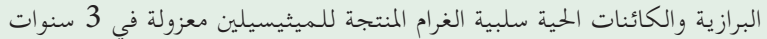

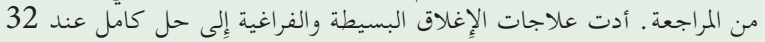

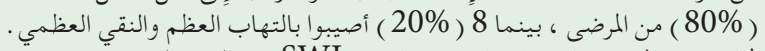

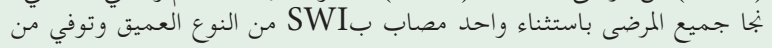
تعفن الدم غير المنضبط المرض باسبناء

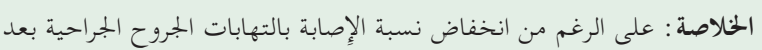

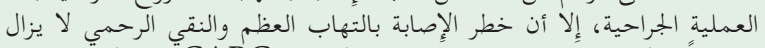

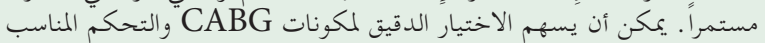

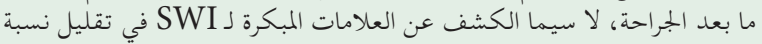

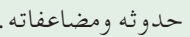

Objectives: To determine the incidence, types, risk factors, identify organisms, and assess outcomes of surgical wound infections (SWIs) after cardiac surgery at a tertiary hospital in Riyadh, Saudi Arabia.

Methods: This historical cohort study reviewed the chart of patients who underwent cardiac surgery at King Khalid University Hospital, Riyadh, Saudi Arabia between January 2009 and December 2014. The proforma contained personal data, comorbidities, type of surgery, microbiological analysis, and management outcomes.
Results: A total of 1241 patients were enrolled in the study comprising 1,032 (83.2\%) men and 209 (16.8\%) women. Forty (3.2\%) patients developed SWI, of which $32(2.5 \%)$ were superficial and $8(0.7 \%)$ were deep. Gender, obesity, diabetes mellitus, non-use of statins, and coronary artery bypass graft (CABG) surgery were not significant predictors of infection in the study. Methicillin-susceptible Staphylococcus aureus was isolated predominantly in 45\%, followed by Klebsiella and Pseudomonas species. Methicillin-resistant Staphylococcus aureus, Enterococcus faecium, and extended $\beta$-lactamaseproducing gram-negative organisms were pathogens isolated in last 3 years of the review. Simple and vacuum assisted closure therapies led to complete resolution in $32(80 \%)$ patients, while $8(20 \%)$ developed sternal osteomyelitis. All patients survived except one with a deep SWI who died of uncontrolled sepsis.

Conclusion: Despite the low incidence of postoperative SWIs, the risk of sternal osteomyelitis development persists. Meticulous choice of CABG components and appropriate postoperative management, especially detecting early signs of SWI could contribute to lower its incidence and complications.

Keywords: surgical wound infection, sternotomy, risk factors, outcomes

Saudi Med J 2020; Vol. 41 (2): 177-182 doi: 10.15537/smj.2020.2.24843

From the Department of Infectious Diseases (Al Majid, Barry, Alsharani), King Saud University; from the Department of Medicine (Alfawzan) King Khalid University Hospital, Riyadh, Kingdom of Saudi Arabia; and form the Department of Medicine (Buba), College of Medicine Sciences, University of Maiduguri, Maiduguri, Nigeria.

Received 22nd July 2019. Accepted 8th December 2019.

Address correspondence and reprint request to: Dr. Fahad M. Al Majid, Department of Infectious Diseases, King Saudi University, Riyadh, Kingdom of Saudi Arabia.E-mail: falmajid@gmail.com ORCID ID: https://orcid.org/0000-0003-2719-5103 
T he first sternotomy was performed for the excision of tuberculous mediastinal lymph nodes by Dalton et al. ${ }^{1}$ It became subsequently the standard for cardiac surgery from the late 1990s' The majority of studies on surgical wound infections (SWIs) after cardiac surgery reported mainly on deep SWIs with incidence rates differing from $0.4 \%$ to $2.3 \% .^{2,3}$ Surgical wound infections are divided into superficial and deep types with emphasis to either involvement of the subcutaneous tissue only or accompanied by sternal osteomyelitis with or without mediastinitis. ${ }^{4,5}$ Deep SWI is a serious complication with mortality rates between $15 \%$ and $47 \%{ }^{2,6,7}$ though lower rates from $5 \%$ to $15 \%$ were also reported by other studies. ${ }^{2,8}$ Identification of the various risk factors is imperative for prevention and management of SWI. The present study was conducted aiming to determine the incidences, types, risk factors, identify organisms and assess outcomes of SWIs in patients who underwent cardiac surgery.

Methods. We conducted a historical cohort study of the chart from our hospital database of 1,241 consecutive patients who underwent cardiac surgery by median sternotomy at King Khalid University Hospital, Riyadh, Saudi Arabia between 2009 and 2014, with the aim of identifying patients with sternal wound infections after cardiac surgery. Ethical approval was obtained from the institutional review board of the hospital. The following data were collected from the medical records: demographic characteristics, including age and gender; comorbidities; duration and type of surgery; microbiological culture reports; and clinical outcomes, which included the date of death or hospital discharge. Surgical wound infections were classified as follows: superficial SWIs, where the infection was confined to the skin and subcutaneous tissue, and deep SWIs, where the infection was associated with sternal osteomyelitis with or without infection of the retrosternal space. ${ }^{4,5,9}$ Clinical evidence of cellulitis and a positive bacterial culture with $\geq 10^{5}$ colony-forming units were used as inclusion criteria for the diagnosis of SWI. Samples for microscopy, culture and susceptibility were collected via deep swabbing, tissue collection and pus aspiration. Retrosternal space collection was established by computed tomography scan of the chest. The pre- and intraoperative risk factors including nasal

Disclosure. Authors have no conflict of interests, and the work was not supported or funded by any drug company. colonization, body mass index, diabetes mellitus, use of lipid lowering drugs and duration of surgery were evaluated. They were also compared between patients who developed SWIs and those who did not. Nasal swab was routinely performed for all patients before cardiac surgery. Positives cultures were treated with appropriate local antibiotics with repeat cultures to confirm eradication of colonization. The results of the preoperative bacterial screening from the nasal canal were obtained for every patient through the laboratory information system. All patients as part of standard hospital policy were provided intravenous cefazolin for antimicrobial prophylaxis from time of intubation to a maximum of 72 hours.

Statistical analysis. We calculated the incidence of postoperative SWI. Categorical variables were expressed as frequencies and proportions. Risk factors for SWI were explored using odds ratios (ORs) plus their respective $95 \%$ confidence interval (CI) and binary logistic regression between the dependent variable (SWI) and the independent variables. Statistical analysis was performed using Statistical Package for Social Sciences for Windows, version 20.0 (IBM Corp, Armonk, NY, USA).

Results. A total of 1,241 patients who underwent cardiac surgery during the study period were included, of which 1,032 (83.2\%) were men and 209 (16.8\%) were women. Surgical wound infections occurred in $40(3.2 \%)$ patients, of which $32(2.5 \%)$ had superficial SWIs (skin and subcutaneous tissue), while $8(0.7 \%)$ showed deep SWIs (complications of bone osteomyelitis with/without retrosternal space collection). Among the patients with SWIs, 25 (62.5\%) were men and 29 $(72.5 \%)$ had a history of diabetes mellitus (Table 1$)$. Furthermore, $33(82.5 \%)$ patients underwent different types of coronary artery bypass graft (CABG) surgery; of these, $29(72.5 \%)$ patients underwent left internal mammary artery graft placement. None of the patients requiring CABG underwent bilateral internal mammary arteries graft placement. Other categories of cardiac surgery in patients recruited into the study were: valvular repair/replacement and repair of congenital heart defects. None of the risk factors consisting of gender, CABG surgery, obesity, use of statins, smoking, diabetes mellitus and duration of surgery were statistically significant risk factors in this study (Table 2). In addition, logistic regression analysis revealed none as an independent predictor of SWI in this study (Table 3). Methicillin-susceptible Staphylococcus aureus (MSSA) was the causative agent in 18 (45\%) patients; methicillin-resistant $S$. aureus (MRSA), Klebsiella 
Table 1 - Pattern of parameters and outcomes in patients $(\mathrm{N}=40)$.

\begin{tabular}{lrc}
\hline Parameter & n $(\%)$ \\
\hline Men & $25(62.5)$ \\
Women & $15(37.5)$ \\
Smoker & $10(25.0)$ \\
Diabetes mellitus & $29(72.5)$ \\
Use of lipid lowering drugs & $31(77.5)$ \\
Resolution of infection & $32(80.0)$ \\
Osteomyelitis & $8(20.0)$ \\
Type of graft & & \\
SVG & 1 & $(2.5)$ \\
SVG + LIMA & 1 & $(2.5)$ \\
SVGs (2) + LIMA & $20(50.0)$ \\
SVGs (3) & 2 & $(5.0)$ \\
SVGs (3) + LIMA & $8(20.0)$ \\
SVGs (4) & 1 & $(2.5)$ \\
None & $7(17.5)$ \\
\hline SVG: saphenous venous graft, LIMA: left inferior \\
\multicolumn{2}{c}{ mammary artery } \\
\hline
\end{tabular}

species, and Pseudomonas species were the other causative agents with $5(12.5 \%)$ patients infected by each of them (Table 4). The patient who developed SWI with MSSA were substantially males with diabetes mellitus and who underwent CABG operation. The last 3 years of the review recorded 11 isolates $(27.5 \%)$ with organisms that were inherently resistant or difficult to treat, such as MRSA, Enterococcus faecium, and extended $\beta$-lactamase-producing gram-negative organisms. Only 2 of 40 patients with SWIs showed positive nasal carriage of MSSA prior to surgery.

Discussion. Despite the reduction in the incidence rate to between $1 \%$ and $4 \%$ in all cardiac surgery procedures, postoperative SWIs are associated with increased morbidity and mortality and decreased life expectancy in the long term..$^{2,10,11}$ In the Middle East, few studies have reported the frequency of SWIs for

Table 2 - Association between risk factors in study population with and without SWI.

\begin{tabular}{|c|c|c|c|c|}
\hline \multirow[t]{2}{*}{ Parameter } & \multicolumn{2}{|c|}{ SWI } & \multirow[t]{2}{*}{ Odds ratio $(\mathrm{CI})$} & \multirow[t]{2}{*}{$P$-value } \\
\hline & Yes & No & & \\
\hline \multicolumn{5}{|l|}{ Gender } \\
\hline Male & $25(2.4)$ & $1007(97.6)$ & $0.371(0.108-1.268)$ & 0.111 \\
\hline Female & $15(7.2)$ & $194(92.8)$ & & \\
\hline \multicolumn{5}{|l|}{ Smoking } \\
\hline Yes & $10(2.4)$ & $402(97.6)$ & $1.004(0.297-3.393)$ & 0.995 \\
\hline No & $30(3.6)$ & $799(96.4)$ & & \\
\hline \multicolumn{5}{|c|}{ Diabetes mellitus } \\
\hline Yes & $29(4.0)$ & $691(96.0)$ & $2.189(0.584-8.206)$ & 0.374 \\
\hline No & $11(2.1)$ & $510(97.9)$ & & \\
\hline \multicolumn{5}{|c|}{ Use of lipid lowering drugs } \\
\hline Yes & $31(3.4)$ & $874(96.9)$ & $1.112(0.294-4.184)$ & 0.875 \\
\hline No & $9(2.7)$ & $327(97.3)$ & & \\
\hline \multicolumn{5}{|l|}{ Obesity } \\
\hline Yes & $13(4.9)$ & $255(95.1)$ & $1.247(0.330-4.708)$ & 0.723 \\
\hline No & $27(2.8)$ & $946(97.2)$ & & \\
\hline \multicolumn{5}{|l|}{$C A B G$} \\
\hline Yes & $33(2.9)$ & $866(96.4)$ & $1.057(0.281-3.979)$ & 0.935 \\
\hline No & $7(2.2)$ & $315(97.8)$ & & \\
\hline \multicolumn{5}{|c|}{ Duration of surgery } \\
\hline$>4$ hours & $21(3.1)$ & $661(96.9)$ & $0.824(0.261-2.597)$ & 0.740 \\
\hline$<4$ hours & $19(3.4)$ & $540(96.6)$ & & \\
\hline
\end{tabular}

Table 3 - Multiple linear regression analysis for predictors of sternal wound infection.

\begin{tabular}{lcc}
\hline Variable & Standardized $\beta$ & $P$-value \\
\hline Gender & -1.286 & 0.079 \\
Diabetes mellitus & 0.900 & 0.224 \\
CABG & 0.146 & 0.857 \\
Obesity & 0.035 & 0.960 \\
Use of statins & 0.22 & 0.976 \\
Smoking & 0.344 & 0.616 \\
Duration of surgery $(<4$ versus $>4$ hours $)$ & -0.228 & 0.716 \\
\hline
\end{tabular}


Table 4 - Pattern of causative organisms among patients with sternal wound infections.

\begin{tabular}{lr}
\hline Bacterial species & $\mathbf{n}(\%)$ \\
\hline Staphylococcus aureus (MSSA) & $18(45.0)$ \\
Staphylococcus aureus (MRSA) & $5(12.5)$ \\
Enterococcus & $1(2.5)$ \\
Klebsiella & $5(12.5)$ \\
Pseudomonas & $5(12.5)$ \\
Enterobacter & $4(10.0)$ \\
Escherichia & $1(2.5)$ \\
Serratia & $1(2.5)$ \\
Total & $40(100)$ \\
\hline \multicolumn{2}{c}{ MSSA: methicillin-susceptible Staphylococcus aureus, } \\
\multicolumn{2}{c}{ MRSA: methicillin-resistant Staphylococcus aureus } \\
\hline
\end{tabular}

instance in the review of the first 100 cardiac surgery cases at King Abdulaziz University Hospital, Saudi Arabia an incidence of $1.0 \%$ for deep SWIs was reported. ${ }^{12}$ Sadanandam et $\mathrm{al}^{13}$ in Dubai, reported a $3.6 \%$ incidence of SWIs in 522 patients who underwent coronary artery bypass graft (CABG) surgery. Sharma et $\mathrm{al}^{14}$ evaluated patients who underwent CABG surgery at a community teaching hospital and reported an SWI incidence rate of $3.5 \%$. Both studies were consistent with our findings that demonstrated an incidence of $3.5 \%$. However, in contrast to our findings, previous studies reported SWI incidence rates varying from $0.4 \%$ to $2.3 \% .^{2,3}$ This discrepancy can be attributed to differences in the sample size as well as composition of patients in these study groups.

The predominance of male patients in the study group was largely attributed to the substantial proportion of patients who had undergone CABG surgery. Studies had produced varying results regarding the impact of gender on infective mediastinitis after cardiac surgery. Some studies demonstrated higher incidence of SWIs in male patients. ${ }^{2,15,16}$ Why men are more predisposed compared to women is unclear, but a putative hypothesis suggests that men have more hair follicles along the line of incision of sternotomy hence making them more susceptible to bacterial proliferation and infection. ${ }^{16}$ But carefully designed studies with robust measuring parameters are needed to explore the hypothesis. Other studies nonetheless, demonstrated high incidence in female patients. ${ }^{17,18}$ Our study revealed non-significance of gender as a predictor in the development of SWI after cardiac surgery. In a quantitative analysis of approximately 32 articles, it was shown that a patient's gender does not predict the development of mediastinitis after cardiac surgery for children or adults. ${ }^{19}$

The majority of patients recorded in this study were middle-aged patients who required CABG surgery and had a history of hypertension, dyslipidemia, or diabetes mellitus. In this study, 33 (82.5\%) out of 40 patients underwent CABG surgery, 29 (72.5\%) of whom underwent left internal mammary artery graft placement. This concurred with the results of previous studies showing an increased incidence of SWIs, especially mediastinitis, in patients with a history of CABG surgery involving the harvest of the internal mammary arteries, ${ }^{13}$ particularly in diabetic and elderly patients. ${ }^{11,20}$ The phenomenon can be attributed to necrosis of the territory when the internal mammary artery is utilized for myocardial revascularization. In addition, the mobilization of the internal mammary artery leads to the reduction of $90 \%$ irrigation of the site of harvest. ${ }^{11}$ None of the patients reviewed in this study underwent bilateral internal mammary arteries harvest probably influencing the overall incidence of SWI.

Previous studies have reported obesity ${ }^{3,21-23}$ and diabetes mellitus ${ }^{4,23}$ as risk factors for the development of SWIs. However, the analysis from our study revealed insignificant contribution of obesity as a predictor to acquiring SWIs probably due the nullifying factors of other variables. An increased intraoperative serum glucose level (>200 mg/dL) has been shown also to be an independent risk factor for postoperative SWI. ${ }^{24}$ Though among the 40 patients in our study, 29 (72.5\%) had already been diagnosed with diabetes mellitus; however, there was no significant association between diabetes mellitus and sternal wound infection.

Staphylococcus aureus and $S$. epidermidis are reportedly the most common pathogens that cause infections in patients following cardiac surgery. ${ }^{2,14,21,23}$ Furthermore, MSSA is likely to be isolated in our study if the individual is male, diabetic, and underwent CABG operation. Other implicated organisms include E. coli, Enterobacter spp, Pseudomonas aeruginosa, and $\beta$-hemolytic streptococci. A study at a cardiac center in Eastern Saudi Arabia ${ }^{25}$ reported the predominance of $S$. epidermidis in SWIs. In our study, 23 of the 40 isolates were $S$. aureus (57.5\%); however, only 2 patients had shown prior nasal carriage of the organism. This discrepancy with our findings may be attributed to factors such as institutional dissimilarities and research design; our study evaluated both clinical and laboratory findings. The worrisome pattern in the last 3 years of the study period is the isolation of resistant organisms, such as MRSA and gram-negative extended-spectrum $\beta$-lactamase-producing organisms. This emerging pattern will present challenges to clinicians with respect to appropriate infection management, isolation measures and proper utilization of antibiotics in clinical practice. 
The management of SWIs has been modernized over time with treatment varying from simple antimicrobial therapy to complete sternotomy, plastic surgery to thoracic wall reconstruction.,26 Cardiac surgery, which is considered a non-contaminating procedure, is peculiar in respect to antimicrobial prophylaxis. However, prophylaxis is suggested as cardiac surgery is frequently intricate with extended period and involving the implant of prosthetic materials. Antimicrobial agents are required to avert springing of organisms. ${ }^{27}$ The Society of Thoracic Surgeons guidelines on antimicrobial prophylaxis in cardiac surgery suggest that cephalosporins be injected within one hour of skin incision and over 24-72 hours after operation. ${ }^{27,28}$ Cephalosporins (cefazolin, cefamandole, cefuroxime, and cefotaxime) are mainly preferred because of their broad-spectrum activity against gram-negative and gram-positive bacteria. Evidence from systematic review promote second- or third-generation cephalosporins for cardiac surgery prophylaxis with indication that extending coverage over 48 hours post-operatively may be advantageous. ${ }^{29}$ Though demonstrated to be effective in treating surgical-site infections following cardiac surgery, their superiority over other antimicrobial agents has not yet been ascertained. Based on the guidelines, all patients in our study received firstgeneration cephalosporins prior to surgery, and nasal carriage of MSSA was treated with local mupirocin ointment with evidence of clearance preoperatively. In our study, 8 patients developed sternal osteomyelitis, though a small subset of patients, a count of $20 \%$ for sternal osteomyelitis is a cause for concern.

We are also aware of the limitations of the study as it is a retrospective cohort study with data obtained from a single medical center. In addition, like all retrospective cohort studies, the inability to demonstrate significant odd ratios may well be due to the convenience sampling leading to possible non-representation of the population and selection bias. Furthermore, the design is liable to recall or misclassification bias. The failure to demonstrate any statistically significant predictor of SWI may likely be also due to skewed proportions between those with and without SWI.

Developments in CABG techniques afford choice modalities to the use of LIMA, such as radial artery graft or right internal mammary artery graft curbing the incidence of infection as well as the possibility of restenosis. ${ }^{30}$ The development of deep SWIs especially in patients with diabetes undergoing CABG surgery can be lessened by harvesting the internal mammary artery in a skeletonized manner. This approach demonstrated excellent protection of sternal blood flow, closure and stability. ${ }^{31,32}$ Therefore meticulous choice of CABG components will hopefully help in reducing deep SWI associated with LIMA graft.

In conclusion, although the incidence of SWI following cardiac surgery is low, there remains a risk for the development of sternal osteomyelitis. Patients undergoing cardiac surgery require appropriate peri-/postoperative management, including an active assessment for early signs of SWI such as redness, pussy discharges and tenderness. This is even more important now as inherently difficult to treat and multi-resistant organisms are becoming important pathogens in SWI.

\section{References}

1. Dalton ML, Connally SR, Sealy WC. Julian's reintroduction of Milton's operation. Ann Thorac Surg 1992; 53: 532-533.

2. Floros P, Sawhney R, Vrtik M, Hinton-Bayre A, Weimers P, Senewiratne $S$, et al. Risk factors and management approach for deep sternal wound infection after cardiac surgery at a tertiary medical centre. Heart Lung Circ 2011; 20: 712-717.

3. Filsoufi F, Castillo JG, Rahmanian PB, Broumand SR, Silvay G, Carpentier A, et al. Epidemiology of deep sternal wound infection in cardiac surgery. J Cardiothorac Vasc Anesth 2009; 23: 488-494.

4. El Oakley RM, Wright JE. Postoperative mediastinitis: classification and management. Ann Thorac Surg 1996; 61: 1030-1036.

5. Tang GHL, Maganti M, Weisel RD, Borger MA. Prevention and management of deep sternal wound infection. Semin Thorac Cardiovasc Surg 2004; 16: 62-69.

6. Baillot R, Cloutier D, Montalin L, Côté L, Lellouche F, Houde $\mathrm{C}$, et al. Impact of deep sternal wound infection management with vacuum-assisted closure therapy followed by sternal osteosynthesis: a 15-year review of 23,499 sternotomies. Eur J Cardiothorac Surg 2010; 37: 880-887.

7. Ridderstolpe L, Gill H, Granfeldt H, Ahlfeldt H, Rutberg H. Superficial and deep sternal wound complications: incidence, risk factors and mortality. Eur J Cardiothorac Surg 2001; 20: 1168-1175.

8. Immer FF, Durrer M, Mühlemann KS, Erni D, Gahl B, Carrel TP. Deep sternal wound infection after cardiac surgery: modality of treatment and outcome. Ann Thorac Surg 2005; 80: 957-961.

9. Anderson DJ, Podgorny K, Berrios-Torres SI, Bratzler DW, Dellinger EP, Greene L, et al. Strategies to prevent surgical site infections in acute care hospitals: 2014 update. Infect Control Hosp Epidemiol 2014; 35: 605-627.

10. Braxton JH, Marrin CA, McGrath PD, Ross CS, Morton JR, Norotsky M, et al. Mediastinitis and long-term survival after coronary artery bypass graft surgery. Ann Thorac Surg 2000; 70: 2004-2007.

11. Dai C, Lu Z, Zhu H, Xue S, Lian F. Bilateral internal mammary artery grafting and risk of sternal wound infection: evidence from observational studies. Ann Thorac Surg 2013; 95: 1938-1945.

12. Jabbad HH, Alebrahim KE. The first one hundred open heart surgeries in King Abdulaziz University Hospital. JKAU Med Sci 2008; 15: 73-79. 
13. Sadanandam R, Al Khaja N, Aziz MA, Turner MA. Profile of coronary artery bypass surgery in United Arab Emirates: Dubai hospital experience. Asian Cardiovasc Thorac Ann 1998; 6: 118-124.

14. Sharma M, Berriel-Cass D, Baran J Jr. Sternal surgical-site infection following coronary artery bypass graft: prevalence, microbiology, and complications during a 42 -month period. Infect Control Hosp Epidemiol 2004; 25: 468-471.

15. Silva QCG, Barbosa MH. Risk factors for surgical site infection in cardiac surgery. Acta Paul Enferm 2012; 25 (Special Issue 2): 89-95.

16. Risnes I, Abdelnoor M, Almdahl SM, Svennevig JL. Mediastinitis after coronary artery bypass grafting risk factors and long-term survival. Ann Thorac Surg 2010; 89: 1502-1509.

17. Ahmed D, Cheema FH, Ahmed YI, Schaefle KJ, Azam SI, Sami SA, et al. Incidence and predictors of infection in patients undergoing primary isolated coronary artery bypass grafting: a report from a tertiary care hospital in a developing country. $J$ Cardiovasc Surg (Torino) 2011; 52: 99-104.

18. Mannien J, Wille JC, Kloek JJ, van Benthem BH. Surveillance and epidemiology of surgical site infections after cardiothoracic surgery in The Netherlands, 2002-2007. J Thorac Cardiovasc Surg 2011; 141: 899-904.

19. Ozturk S, Ozturk I. Does Sex predict the development of mediastinitis? EJMO 2018; 2: 1-7.

20. Omran SA, Karimi A, Ahmadi SH, Davoodi S, Marzban M, Movahedi N, et al. Superficial and deep sternal wound infection after more than 9000 coronary artery bypass graft (CABG): incidence, risk factors and mortality. BMC Infect Dis 2007; 7: 112.

21. Softah A, Bedard A, Hendry P, Masters RG, Goldstein W, Brais $\mathrm{M}$, et al. Wound infection in cardiac surgery. Ann Saudi Med 2002; 22: 105-107.

22. De Feo M, Renzulli A, Ismeno G, Gregorio R, Della Corte A, Utili R, et al. Variables predicting adverse outcome in patients with deep sternal wound infection. Ann Thorac Surg 2001; 71: 324-331.
23. Sa MP, Silva DO, Lima EN, Lima RC, Silva FP, de Rueda FG, et al. Postoperative mediastinitis in cardiovascular surgery. Analysis of 1038 consecutive surgeries. Rev Bras Cir Cardiovasc 2010; 25: 19-24.

24. Gandhi GY, Nuttall GA, Abel MD, Mullany CJ, Schaff $\mathrm{HV}$, Williams BA, et al. Intraoperative hyperglycemia and perioperative outcomes in cardiac surgery patients. Mayo Clin Proc 2005; 80: 862-866.

25. Nagamani R. Bacterial epidemiology of post-operative infections at a cardiac center. Int J Res Med Sci 2016; 4: 4033-4036.

26. Grossi EA, Culliford AT, Krieger KH, Kloth D, Press R, Baumann FG, et al. A survey of 77 major infectious complications of median sternotomy: a review of 7,949 consecutive operative procedures. Ann Thorac Surg 1985; 40: 214-223.

27. Engelman R, Shahian D, Shemin R, Guy TS, Bratzler D, Edwards F, et al. The society of thoracic surgeons practice guideline series: antibiotic prophylaxis in cardiac surgery, part II: antibiotic choice. Ann Thorac Surg 2007; 83: 1569-1576.

28. Edwards FH, Engelman RM, Houck P, Shahian DM, Bridges CR; Society of Thoracic Surgeons. The Society of Thoracic Surgeons practice guideline series: antibiotic prophylaxis in cardiac surgery, part I: duration. Ann Thorac Surg 2006; 81: 397-404.

29. Lador A, Nasir H, Mansur N, Sharoni E, Biderman P, Leibovici L, et al. Antibiotic prophylaxis in cardiac surgery: systematic review and meta-analysis. J Antimicrob Chemother 2012; 67: 541-550.

30. Bakaeen F. CABG: a continuing evolution. Cleve Clin J Med 2017; 84: e15-e19.

31. Deo SV, Shah IK, Dunlay SM, Erwin PJ, Locker C, Altarabsheh $\mathrm{SE}$, et al. Bilateral internal thoracic artery harvest and deep sternal wound infection in diabetic patients. Ann Thorac Surg 2013; 95: 862-869.

32. Sajja LR. Strategies to reduce deep sternal wound infection after bilateral internal mammary artery grafting. Int J Surg 2015; 16 : 171-178. 